2. Museum of Ukrainian Culture in Svidnyk. URL: http://www.snm.sk/ ?muzeum-ukrajinskej-kultury-uvodna-stranka.

3. Fabryka-Protska O. (2019) Functioning of the Slovak-Ukrainian song folklore on the example of the Makovytska Struna festival). Issues of cultural studies. KNUIM Newsletter. Musical Art Series. Vol 2, № 1, Kyiv (in Ukrainian) (in Slovakian)

4. Chizhmar I. (1972) Musical Instruments, Svidnyk: MUK (in Slovakian)

5. Chizhmar I. (2009) Folk Songs, Music and Dance of the Ruthenians of the Original Slovakia. Svidnyk (in Slovakian)

6. Elschek O. (1975) Songs and Music. Slovakia. Lud. Cast II. Bratislava (in Slovakian)

7. Histyria múzea. Muzik Muzeu. URL: https://muzikmuzeum.sk/o-nas/.

8. Smetanka M. O nas. Muzik Muzeu. URL: https://muzikmuzeum.sk/ o-nas/.

УДК 78.01/.08+786.6

DOI https://doi.org/10.31723/2524-0447-2020-30-2-6

\author{
Анна Павловна Копейка \\ ORCID: 0000-0001-6291-9571
}

аспирантка кафедры истории музыки и музыкальной этнографии

Одесской национальной музыкальной академии имени

A. В. Неждановой

anna.kopejka@gmail.com

\title{
СТИЛЕВОЙ ФЕНОМЕН ЖАННЫ ДЕМЕСЬЁ: ИСТОРИЧЕСКИЕ И КОМПОЗИЦИОННЫЕ АСПЕКТЫ
}

Цель работы - создать стилевой портрет выдающейся франиузской органистки, пианистки, композитора середины ХХ века Жанны Демесьё в историческом контексте франиузской органной традиции. Методология исследования состоит в использовании аналитического, биографического, историко-логического, компаративного методов. $\mathrm{Ha}$ учная новизна работы заключается в анализе композиторского метода и выделении стилевых особенностей Жанны Демесьё, чье творчество существенно повлияло на формирование современной франиузской органной школы. В статье приводится краткий исторический очерк основных тенденций франиузской органной школы, сложившихся к началу

(c) Копейка А. П., 2020 
$X X$ века, являющихся фундаментом для целой плеяды композиторов $X X$ века, без рассмотрения которых понимание творческого метода Жанны Демесьё было бы невозможным. Также статья содержит новую информацию биографического характера и хронологический список сочинений композитора, которые в русскоязычной литературе до настоящего времени не были представлены. Выводы. Наследуя многовековые тенденции франиузской органной музыки и преломляя их сквозь призму современной для нее эпохи, Жанна Демесьё обобщает в своем творчестве отдельные традиционные для франиузской школы жканрово-стилевые моменты, среди которых - обращение к религиозно-программной тематике и к григорианскому хоралу в качестве одной из тематических составляющих, значимость колористической составляющей; эти черты она синтезирует с ярко индивидуальными чертами - такими, как рациональность в использовании средств выразительности, трансформирующаяся при необходимости в демонстрацию оркестральных возможностей органа, акустическая продуманность, глубокая содержательная сторона, пианистичность музыкального текста и интересные авторские фактурные находки, а также особый гармонический язык. Произведения Жанны Демесьё по праву входят в анналы мировой органной музыки, однако, к сожалению, мало известны в Украине. Хотелось бы, чтобы данное исследование пробудило интерес к творчеству этой неординарной личности, как у музыковедов, занимающихся проблематикой органного творчества, так и у исполнителей, стремящихся пополнить свой репертуар образцами высокого искусства.

Ключевые слова: Жанна Демесьё, стилевые черты, франиузская органная музыка, ХХ век.

Kopiika Hanna Pavlivna, Graduate Student at the Department of the History of Music and Musical Ethnography of the Odessa National A. V. Nezhdanova Academy of Music

Stylistic phenomenon of Jeanne Demessieux: historical and compositional aspects

Objective of the work is to create a stylistic portrait of an outstanding French organist, pianist, composer of the mid-20th century, Jeanne Demessieux, in the historical context of the French organ tradition. The methodology of the research includes analytical, biographical, historical-logical, comparative methods. The scientific novelty of the work lies in the analysis of the compositional method and the allocation of the stylistic peculiarities of Jeanne Demenies, whose work significantly influenced the formation of the modern French organ school. The article provides a brief historical outline of the French organ school main tendencies had been developed by the beginning of the 20th century, which are the foundation for a whole galaxy of composers of the 20th century, without whose consideration it would be impossible to understand the creative method of Jeanne Demessieu. The article also contains new biographical information and a chronological list of works by the composer, which have not yet been presented in Russian-language literature. Conclusions. Jeanne Demessieu summarizes in her work certain 
genre and stylistic moments, traditional for the French school, among which an appeal to religious-programmatic themes and to the Gregorian chant as one of the thematic components, the significance of the coloristic component; she synthesizes these features with brightly individual features - such as rationality in the use of means of expression, transforming, if necessary, into a demonstration of the organ's orchestral capabilities, acoustic thoughtfulness, a deep content side, the pianism of the musical text and interesting author's textured findings, as well as a special harmonic language. The works of Jeanne Demesieux are rightfully included in the annals of world organ music, however, unfortunately, they are little known in Ukraine. I would like this study to awaken interest in the work of this extraordinary personality, both among musicologists dealing with the problems of organ creativity, and among performers who seek to replenish their repertoire with examples of high art.

Key words: Jeanne Demessieux, stylistic features, French organ music, XX century.

Копійка Ганна Павлівна, аспірантка кафедри історії музики та музичної етнографії Одеської національної музичної академії імені А. В. Нежданової

\section{Стильовий феномен Жанни Демесьйо: історичні і композиційні аспекти}

Мета роботи - створити стильовий портрет видатної французької органістки, піаністки, композитора середини ХХ століття Жанни Демесьйо в історичному контексті французької органної традиції. Методологія дослідження полягає в використанні аналітичного, біографічного, історико-логічного, компаративного методів. Наукова новизна роботи полягає в аналізі композиторського методу і стильових особливостей творчості Жанни Демесьйо, яка суттєво вплинула на формування сучасної франиузької органної школи. У статті наводиться стислий історичний нарис основних тенденцій франиузької органної школи, що склалися на початок ХХ століття та є фундаментом для иілої плеяди композиторів $X X$ століття, без розгляду яких розуміння творчого методу Жанни Демесьйо було б неможливим. Також стаття містить нову інформацію біографічного характеру і хронологічний список творів композитора, які в російськомовній літературі до теперішнього часу не були представлені. Висновки. Наслідуючи багатовікові тенденції франиузької органної музики і пропускаючи їі крізь призму сучасної для неї епохи, Жанна Демесьйо синтезує у своїй творчості окремі традиційні для франиузької школи жанрово-стильові моменти, серед яких - звернення до релігійно-програмної тематики і до григоріанського хоралу в якості однієї з тематичних складових частин, значущість колористичної складової; ці риси вона синтезує з яскраво індивідуальними рисами, такими як раціональність у використанні засобів художньої виразності, що трансформується за необхідності в демонстрацію оркестральності можливостей органу, акустична продуманість, глибока змістовна сторона, піаністичність музичного тексту і иікаві авторські фактурні знахідки, а також особлива гармонічна мова. Твори Жанни 
Демесьйо по праву входять до анналів світової органної музики, проте, на жаль, мало відомі в Україні. Хотілося б, щоб це дослідження пробудило інтерес до творчості цієї неординарної особистості, як у музикознавців, що займаються проблематикою органного творчості, так і у виконавців, які прагнуть поповнити свій репертуар зразками високого мистецтва.

Ключові слова: Жанна Демесьйо, стильові риси, франиузька органна музика, ХХ століття.

Актуальность. Органная музыка занимает особое место в истории человечества. Колоссальный тембральный и динамический спектр органа, позволяющий исполнителю в одиночку уподобляться целому оркестру, породил вокруг этого инструмента особый мистический ореол. В настоящее время интерес к этому инструменту все возрастает, регулярно исполняются произведения различных музыкальных эпох, в числе которых видное место занимает пласт современной музыки. Исполнителям-органистам важно хорошо ориентироваться в репертуape, расширять его произведениями, которые не оставят слушателей равнодушными. Данная статья предлагает вниманию обзор творчества Жанны Демесьё - настоящей сокровищницы для исполнителей, слушателей и исследователей.

Цель работы - познакомиться с основными этапами жизненного и творческого пути Жанны Демесьё в контексте исторической эпохи и французской органной школы; сделать обзор творческого наследия композитора и выделить особенности ее авторского стиля.

Основное содержание. Жанна Демесьё (Jeanne Demessieux) легендарная французская органистка, пианистка и композитор середины XX в., первая женщина-виртуоз международного уровня. Ее считают одним из «титанов» органа, однако, несмотря на этот легендарный статус, она остается одной из самых загадочных героинь этого инструмента.

Жанна Демесьё ${ }^{1}$ родилась 13 февраля 1921 года в Монпелье, одном из крупнейших городов на юге Франции. Родители Жанны любили музыку и часто ходили на концерты. Раннее музыкальное образование Жанна получила под чутким руководством своей сестры, на 13 лет старше ее, которая к тому возрасту уже была прекрасной пианисткой и органисткой. В возрасте 11 лет Жанна выиграла первую премию за интер-

${ }^{1}$ Биографические сведения почерпнуты из литературных источников $[2 ; 4]$. 
претацию фортепианного концерта Видора. Будучи убежденными в исключительном таланте своей дочери и понимая, что ресурсы их южной провинции оказались для нее исчерпаны, родители приняли решение переехать в Париж.

Застенчивая девушка совершенно очаровала своим талантом парижских мэтров, и Жанна была зачислена в консерваторию в класс Симона Риера (Simon Riera), с которым она часто конфликтовала, однако в обучении продвигалась замечательно. Например, однажды в 8-дневный период она освоила 2 трансцендентных этюда и Венгерскую рапсодию № 6 Листа, сонату ор. 106 Бетховена, хроматическую фантазию и фугу Баха и несколько этюдов Шопена!

Что же побудило Жанну обратиться к органу, имея такие блестящие перспективы в области фортепиано? Во всем оказалась виновата, как это часто бывает, случайность. Переехав в Париж и будучи католиками, Жанна и ее семья присоединились к недавно построенной церкви Сен-Эспри (йglise du Saint-Esprit). Осознавая талант девочки, 12-летнюю Жанну попросили быть органисткой этой церкви. Поначалу, пока орган не установили, она играла на фисгармонии. Когда же через год инструмент был установлен, встал вопрос о том, чтобы найти для нее подходящего учителя. Для Жанны организовали прослушивание у знаменитого органиста и композитора Марселя Дюпре, профессора парижской консерватории (среди учеников которого был, в частности, Оливье Мессиан). Тот день 8 октября 1936 года изменил весь ход ее жизни. Впечатления от знакомства с Дюпре выразились в ее дневнике словами: «Незабываемое rendez-vous!»

Так Жанна стала ученицей Марселя Дюпре, под чьим руководством она впоследствии проработает долгие годы, не покладая рук. Дюпре нашел в ней своего долгожданного преемника, которому он мог бы передать эстафету славной традиции французского органного искусства, «доставшуюся» ему в свое время от учителя Шарля-Мари Видора.

В годы оккупации, когда немцы занимали Париж, и свобода была сильно ограничена, Жанна регулярно ходила на виллу Дюпре, находящуюся более чем в шести милях от центра Парижа (почти 10 км). В эти годы она работала с лихорадочной напряженностью (иногда 18 часов в день). В дальнейшем она отмечала, что только увлеченность музыкальными исследованиями помогла ей пережить ужасы оккупации. 
В 1946 году Марсель Дюпре и его жена Жанна Дюпре, взявшая на себя административные вопросы, организовывали серию концертов в зале Плейель, успех которых оказался колоссальным. Но покорением парижской публики планы Дюпре не исчерпались. 26 февраля 1947 года Жанна выступила с концертом в Вестминстерском соборе в Лондоне. Это было началом международного признания Жанны Демесьё. Вскоре приглашения посыпались со всех сторон.

Дюпре загорелся намерением познакомить со своей воспитанницей американскую публику, он видел в ней качества, которые могли сделать ее звездой. Тем не менее, эта идея не нравилась Жанне, и она наотрез от нее отказалась. И Дюпре отправился в турне по Америке один. После своего возвращения он никогда с ней не разговаривал и жестоко пресекал любые попытки примирения.

Эта ссора фатально отразилась на ее карьере в Париже. Однако вне Франции ее встречали с энтузиазмом. В конце концов она побывала и в США (в 1953, 1955 и 1958), что раскрыло перед ней множество перспектив. Тем не менее Жанна отказалась от дальнейших приглашений и выступлений в штатах, выражая обеспокоенность оставленными стареющими родителями.

На протяжении многих лет своей деятельности Жанна осуществила более 600 сольных концертов по всей Европе и Северной Америке, сделала ряд аудиозаписей, благополучно дошедших до нас, из которых мы можем сделать заключение о ее исключительном артистизме и выразительной музыкальности, далекой от пустой технической беглости.

Помимо концертной, она вела также преподавательскую деятельность. В 1950 году она была назначена профессором органа в консерватории в Нанси; в 1952 году - на тот же пост в Королевской консерватории Льежа.

Кроме того, Жанна серьезно относилась и к своей роли церковного органиста, она проработала 29 лет в церкви Сен-Эспри, затем - в одной из самых важных церквей Парижа, Мадлен.

В 1962 году она стала кавалером ордена Короны Бельгии.

Жанна Демесьё занимается также и композиторской деятельностью. Среди поклонников ее творчества были, в частности, Ф. Пуленк и О. Мессиан. Мессиан часто приглашал ее в жюри во время экзаменов в своем классе в консервато- 
рии, что говорит о глубоко уважительном отношении к ней. В начале 60-х Мессиан хотел организовать запись полного собрания ее сочинений, однако этому проекту не суждено было реализоваться.

Постоянная борьба со слабым здоровьем, с заболеванием раком были еще одним тяжким бременем в ее жизни. 11 ноября 1968 года ее не стало.

За свою, к сожалению, недолгую жизнь Жанна Демесьё сумела достичь высочайшего уровня мастерства, оказать большое влияние на формирование мирового искусства и французской органной музыки в частности.

Творчество Жанны Демесьё, развиваясь и формируясь под влиянием выдающихся органистов Парижа I половины XX века, впитало в себя лучшие традиции французской органной традиции, корни которой уходят в глубину эпох. Однако сейчас мы не будем говорить о «корнях», выделим из недр истории лишь промежуток, длиной примерно в столетие, непосредственно предшествовавший жизни Жанны Демесьё.

В XIX веке во Франции происходит несколько кардинальных изменений в области органного искусства [1]. Первое возникновение ряда специальных учебных заведений, где органисты начинают получать академическое музыкальное образование, включающее обучение гармонии, контрапункту, форме наряду с собственно технической подготовкой на инструменте (до сих пор секреты мастерства передавались церковными музыкантами от учителя к ученику частным образом). Одним из таких учебных заведений была Парижская консерватория, в стенах которой впоследствии вырастет Жанна. Второе кардинальное изменение связано с переворотом во французском органостроении, который совершает $A$. Кавайе-Коль в середине XIX века. Он выдвигает новую концепцию органа - симфонического, - соответствующего романтической эпохе. Кардинально меняется состав и характер регистров ${ }^{2}$, что открывает перед компо-

2 Добавляется множество регистров, имитирующих оркестровые духовые инструменты (гобой, кларнет, фагот, английский рожок); эффект forte достигается теперь с помощью прибавления батареи язычковых регистров Bombarde 16', Trompette 8', Clairon 4', роль которых в романтических экстатических кульминациях подобна функции группы медных 
зиторами и органистами небывалые доселе просторы и возможности.

Таким образом, во французской органной музыке начинается новая эпоха. И открывается она во II половине XIX века двумя именами, представляющими два полюса в развитии французской музыки, это - Камилл Сен-Санс, воплощающий типично французское начало, с его тяготением к театральности, внешней броскости, приятности, и в то же время стройности, логичности, даже классичности в высказывании, и Сезар Франк, тяготеющий к немецкой многозначительности, рефлексии, внесший философский строй во французскую инструментальную музыку [3].

Именно с этого момента в сферу органной музыки начинают просачиваться приемы фортепианной техники: октавы, аккордовые репетиции, разнообразные арпеджио, двойные ноты вкрапляются в традиционное органное письмо, опиравшееся прежде в большей степени на барочные полифонические традиции. Многие из наметившихся тогда тенденций мы наблюдаем и в творчестве Жанны Демесьё, которая была прекрасной пианисткой, прошла блестящую фортепианную школу к моменту начала изучения особенностей органного исполнительства.

K восьмидесятым годам XIX века во французской органной музыке - в опусах Франка, Сен-Санса, их младших современников - Видора, Гильмана, Лорета, Жигу, Бельмана - складываются основные жанровые направления, по которым пойдет дальнейшее развитие французской органной музыки в XX веке.

1. Симфоническое, в русле которого работали Ш. Видор, А. Гильман, Л. Вьерн, создавая свои циклы монументальных симфоний для органа соло, а также органные сонаты, прообразом которых был четырехчастный сонатно-симфонический цикл немецких композиторов.

духовых, прорезающих звучность симфонического оркестра. Добавляется новое семейство язычковых - шамады, тембр которых отличается особой пронзительностью: добавляются регистры, являющиеся «визитной карточкой» Кавайе-Коля семейство Flutes harmoniques или Octavians («гармонические» флейты, дающие октавный обертон и имитирующие эффект передувания), а также регистры Voix celeste, Unda maris (в которых одна из труб настраивается выше или ниже основного строя, что вызывает эффект «биения», передающийся через колебание или легкое тремоло звука). 
2. Неоклассическое или необарочное, связанное с обращением к формам и жанрам полифонического стиля эпохи Барокко - прежде всего к фуге, имитационной технике.

3. Жанрово-программное, наиболее характерное для французского искусства. Самым ярким представителем этой линии был Луи Вьерн.

4. Религиозно-программное. Едва ли не все французские композиторы рубежа XIX-XX веков отдали дань этому направлению. Богатые тембровые возможности органа неожиданным образом оказались как нельзя более подходящими для выражения религиозных идей.

5. Органная музыка, предназначенная для сопровождения богослужения. Истоки этой области органного искусства в изначальной предназначенности органа как литургического инструмента.

Эти жанровые направления широко представлены и в творчестве Жанны Демесьё.

Во французской органной музыке мы наблюдаем явление, отличающее эту школу от других мировых органных школ: светский жанр симфонии поворачивается в сторону церкви. И одним из первых композиторов, использовавших мелодии католической литургии в симфоническом произведении, становится Видор (в своих органных симфониях).

Среди композиторов, оказавших большое влияние на развитие французского органного искусства, нельзя не упомянуть Луи Вьерна, прямого наследника Франка и Видора. По своему духу, стилистике музыка Вьерна отвечает эстетике постромантизма. Вьерн прежде всего лирик, и для выражения личных чувств и переживаний ему как нельзя более подходят формулы романтического языка. Из современной ему фортепианной техники Вьерн заимствует импрессионистические фактурные приемы, позволяющие создать подвижный гармонический фон. В его симфониях можно встретить длинные линии кварто-квинтовых, кварто-секстовых фигураций, параллельное движение секстами (часто с вкраплениями проходящих хроматизмов), на которые наслаивается с одной стороны - мелодия, с другой - гармонический бас, удерживающий вертикаль в рамках классической тональности.

Отдельные фактурные, эстетические и концептуальные моменты, применяемые Вьерном (подвижная «дышащая» фактура, красочность, выражение музыкой личного и пр.), 
оказали влияние и на композиторскую технику Жанны Демесьё.

Однако из всех мастеров органистов того времени самое большое влияние оказал на нее ее учитель, Марсель Дюпре. Вспомним, что в определенный период своей жизни именно Жанна была первым интерпретатором и исполнителем его произведений. Как черту стиля Марселя Дюпре отметим отсутствие мелодически развернутых тем. Дюпре свойственно интервальное мышление, и его темы - это чаще всего определенные интервальные ходы, многократно повторяющиеся на разной высоте. Зато эти неяркие в мелодическом плане темы обретают рельеф благодаря оригинальной тембровой окраске. Дюпре вообще расширяет диапазон органа, постоянно используя крайние октавы. Он обыгрывает особенности звучания этих регистров - глухой тембр большой и малой октавы и тонкий пронзительный - в третьей октаве, добиваясь ярких звукоизобразительных эффектов. В сфере регистровки он предпочитает «чистые» краски. Например, часто встречаются «хоры» регистров одного семейства, взятые с разных мануалов, сольные тембры (Flute, Trompette, Gambe), не смешанные с другими регистрами. Многие из этих моментов находят свое выражение и в произведениях его ученицы

$$
* * *
$$

Жанна Демесьё известна в первую очередь своими сочинениями для органа, которые вошли в репертуары многих выдающихся органистов и продолжают звучать с различных сцен мира, покоряя сердца слушателей. Однако, она автор не только органной музыки. Ее творческое наследие включает также:

- фортепианные сочинения («Колыбельная», 1926 г., «Сюита», 1938 г., «Этюд Fis-dur», 1938 г., «Три прелюдии», 1939 г.);

- произведения для голоса и фортепиано («Le moulin» «Мельница», 1937 г., «Soudainement contre les vitres»- «Внезапно у оконного стекла», 1940 г., «Sonnet de Michel-Ange» - «Сонет Микеланджело», 1949 г., «Action de grвсе» - «Благодарение», «Cavalier» - «Рыцарь», «Le vase brisй» - «Разбитая ваза»);

- камерную музыку (Соната для скрипки и фортепиано, 1940 г., «Баллада», ор.12, для валторны и фортепиано, 1962 г., Струнный квартет); 
- вокальную музыку («Cantate pour le jeudi Saint» - «Кантата на Чистый четверг» для хора, солистов и органа на сл. Феликса Рожеля, «Barques cйlestes»- «Небесные лодки» для трех женских голосов a capella, 1950 г., «Chanson de Roland» - «Песнь о Роланде» для хора, меццо-сопрано и оркестра, 1951-56 гг.);

- разное (Два симфонических момента для оркестра, 1941 г., Г.Ф. Гендель Каденции для органа к концертам № 1, 2, Ф. Лист «Funйrailles» - аранжировка для органа соло).

Ocoбое место в творчестве Жанны занимает «Роште» («Поэма»), ор. 9, 1949 г. для органа с оркестром, в которой краски органа удивительным образом сочетаются и диалогизируют с оркестровыми, создавая то эффект соперничества между этими двумя монументальными силами, то иллюзию полного растворения одного в другом.

Но самыми многочисленными и значимыми в пространстве мировой музыки являются сольные органные сочинения Жанны Демесьё. Среди них:

- Nativitŭ - «Poжdecmвo», op. 4, 1943/44 г. (Sampzon: Delatour France, 2005);

- Six ŭtudes - «Шесть этюдов», ор. 5, 1944 г.

- Sept müditations sur le Saint-Esprit - «Семь размышлений о Святом Духе», ор. 6, 1945-47 гг. (Paris: Durand, 1947)

- Triptyque - «Tpunmux», op. 7, 1947 г. (Paris: Durand, 1949)

- Twelve Choral-Preludes on Gregorian Chant Themes «Двенадцать хоралов на григорианские напевь",, ор. 8, 1947 г. (Boston, MA: McLaughlin \& Reilly, 1950)

- Andante (Chant donnǔ), 1953 г. (In: 64 Lezons d'Harmonie, offertes en hommage a Jean Gallon, edited by Claude Delvincourt. Paris: Durand, 1953)

- Te Deum, op. 11, 1957/58 гг. (Paris: Durand, 1959)

- Rüpons pour le temps de pвques: Victimae paschali laudes, 1962/63 гг. (Paris: Durand, 1970)

- Rüpons pour les temps liturgiques, 1962-66 гг. (Sampzon: Delatour France, 2006)

- Prülude et fugue en ut, op. 13, 1964 г. (Paris: Durand, 1965)

Настоящим «профессиональным вызовом» для органистов является цикл «Шесть этюдов», ор. 5: 1. Pointes, 2. Tierces, 3. Sixtes, 4. Accords alternйеs, 5. Notes rйрйtйеs, 6. Octaves. Это шесть написанных на разные виды техники произведений, необычайно виртуозных, требующих от исполнителя не только мастерского владения органом, но и способности 
воплощать художественное начало, которое является в этих этюдах доминирующим, несмотря на все технические сложности.

Жанна, будучи органисткой высочайшего мастерства, сочетала в себе обе эти исполнительские стороны. До нас дошли аудиозаписи ее исполнения произведений Г. Пёрселла, И. С. Баха, В. А. Моцарта, С. Франка, Ф. Листа, Ш. М. Видора, О. Мессиана, Ж. Бервейе, некоторых из еe авторских сочинений, среди которых Те Deum op. 11; Consolateur (Sept Mйditation sur le Saint Esprit op. 6), Tierces (Six Йtudes op. 5).

Небольшая доля ее репертуара, дошедшая до нас в аудиозаписях, выявляет обширность ее музыкально-исполнительского кругозора, на фундаменте которого сформировался в процессе совмещения композиторско-исполнительской деятельности ее авторский органный стиль, об особенностях которого сейчас и пойдет речь.

Очень показательным в творчестве Жанны Демесьё является цикл «Семь размышлений о Святом Духе», ор. 6. Номера цикла высвечивают разные грани этого вопроса: 1. Veni Sancte Spiritus - «Приди, Дух Святой»; 2. Les Eaux («Вода»); 3. Pentecфte («Пятидесятница»); 4. Dogme («Догма»); 5. Consolateur («Утешитель»); 6. Paix («Мир»); 7. Lumiиre («Свет»). Каждый номер предваряется словестным эпиграфом, дающим ключ к пониманию образно-содержательной стороны музыки. Цикл может исполняться как целиком, с каждым эпизодом все более погружая в свое содержание и «растворяя» в себе образные интенции исполнителя, так и в виде отдельных номеров. Особой популярностью пользуется № 7 цикла - Lumiиre («Свет»). Мягкие, струящиеся и мерцающие звуки органа удивительным образом обретают способность светиться, бесконечный поток неземных лучей льется на слушателей и окутывает собой каждую частичку звучащего пространства. Завораживающая колористичность в сочетании с детальной композиционно-исполнительской продуманностью позволяют относить это произведение к жемчужинам мирового органного наследия.

Цикл «Двенадцать хоралов на григорианские напевы», ор. 8, занимает особое место в творчестве Жанны Демесьё. В нем гармонично сочетаются относительная (в сравнении с другими произведениями) техническая простота и глубокая 
содержательность, обращение к исторической традиции и оригинальное авторское прочтение. Номера цикла повествуют о самых значимых эпизодах христианства, и каждый из них предстает в своем персональном стилистическом и жанровом выражении: 1. Rorate caeli (Choral ornü); 2. Adeste Fideles (Musette); 3. Attende Domine (Choral paraphrase); 4. Stabat mater (Cantabile); 5. Vexilla Regis (Prelude); 6. Hosanna Filio David (Choral fugue); 7. Filii (Variations); 8. Veni Creator (Toccata); 9. Ubi Caritas (Ricercare); 10. In Manus Tuas (Litanie); 11. Tu Es Petrus (Marcia); 12. Domine Jesu (Berceuse).

$* * *$

Наследуя многовековые тенденции французской органной музыки и преломляя их сквозь призму современной для нее эпохи, Жанна Демесьё синтезирует в своем творчестве отдельные традиционные эстетические композиционные приемы (многие из которых характерны именно для французской музыки) с ярко индивидуальными выразительными средствами. Из традиционных можно отметить обращение $\kappa$ религиозно-программной тематике и $\kappa$ григорианскому хоралу в качестве одной из тематических составляющих. Однако взаимодействие вобравшего в себя глубокий исторический опыт хорала с яркой стилевой индивидуальностью Жанны порождает уникальное явление в истории органной музыки, при котором происходит не противопоставление эпох, а сокращение дистанции между давностью и современностью. Во многих хоральных прелюдиях Жанна прибегает к стилизации, не перенося нас в историческое прошлое, а наблюдая за ним извне, свободно распоряжаясь характерными для той эпохи выразительными средствами, наряду с чуждыми ей. Благодаря этому создается особый многомерный семантический диалог, погружающий нас в переживание христианских событий как бы с разных отправных точек в одновременности. При этом не возникает стилистического диссонанса и ощущения разнородности в музыкальном языке, напротив - мы ощущаем подчиненность всех используемых композитором средств одной общей художественно-содержательной идее.

Обращает на себя внимание высокая степень композиционной продуманности произведений Жанны, рациональность в использовании средств выразительности, отсутствие композиционных излишеств, не оправданных драматургической концепцией. Это проявляется и в фактурно-гармоническом 
содержании, и в темброво-регистровой стороне органных произведений.

Отличительной особенностью произведений Жанны Демесьё является их гармонический язык. Особенно явственно это проявляется в цикле «12 хоральных прелюдий на григорианские напевы», во многих номерах которого стилизованные эпизоды, исполненные в манере традиционного гармонического письма, перемежаются с неожиданными гармоническими оборотами, выдающими в них присутствие авторского стиля, порожденного сознанием иной эпохи. Характерной особенностью гармонического стиля Жанны является игра с консонансно-диссонансной средой, когда аккорды терцовой структуры свободно перемежаются с нетерцовыми и даже кластерными созвучиями, и такое сгущение-разрежение звучности воспринимается без негативной смысловой нагрузки, как естественная гармоническая стереоскопичность.

Помимо духовных традиций, уходящих корнями глубоко в историю органной музыки, в творчестве Жанны Демесьё проявляются отдельные черты романтического стиля (личностное отношение к раскрывающейся тематике, обращение к сквозным формам, поэмность отдельных эпизодов). Можно выделить моменты, характерные для импрессионистов-символистов (внимание к колористическому фактору и звукоизобразительной составляющей произведения, увлечение образами, связанными с природными явлениями и стихиями - вода, воздух, свет). Однако приемы работы с тематизмом, гармонический язык и общая стилистика не оставляют сомнения в том, что Жанна Демесьё - композитор середины XX века.

В произведениях Жанны проявляется и оркестральность, ставшая «визитной карточкой» французских композиторов-органистов начиная с середины XIX века, момента переворота в органостроении, совершенного Кавайе-Колем, выдвинувшем концепцию «симфонического органа». Оркестральность в музыке Жанны Демесьё находит свое выражение в многослойности фактуры (доходящей иногда до пяти самостоятельных тембрально различающихся линий, как, например, во второй части цикла «Семь размышлений о Святом Духе»), а также в принципе контрастности, наподобие оркестрового сопоставления сольного звучания какого-либо инструмента (либо камерного состава группы инструментов) с туттийным звучанием всего оркестра. 
Жанна унаследовала от своего учителя Марселя Дюпре композиционные приемы, основывающиеся на работе $c$ мотивом как главным элементом и тематическим зерном произведения. Мотивы, повторяющиеся на разной высоте, полифонически наслаивающиеся друг на друга с применением различных имитационных приемов, благодаря тембровой окраске обретают рельеф (это наблюдается во многих номерах цикла «Семь размышлений о Святом Духе»).

Следует отметить акустическую продуманность произведений Жанны Демесьё, ее владение звуковым пространством. Архитектурные особенности храма с его купольными сводами и масштабами, позволяющими вмещать большое количество человек, оказали влияние и на фактурные особенности ее произведений, в ряде которых наблюдается большое количество фигураций и общих форм движения, как бы заполняющих собой пространство храма. Эти фигурации обволакивают слушателей, погружая и растворяя их в звуках.

Говоря об особенностях стиля Жанны Демесьё, нельзя не упомянуть пианистичность ее произведений. Имеется в виду как «удобность» фактуры для исполнителя, так и внедрение различных фортепианных технических приемов в область органной музыки, трансформировавшихся с учетом особенностей органа, одной из которых является наличие в органе нескольких мануалов и отдельной педальной клавиатуры. Яркой иллюстрацией этого тезиса служит седьмая часть «Размышлений» - «Свет».

Эта же часть обращает внимание на интересный прием, связанный с «игрой тембрами», когда один и тот же звук, встречаясь в рамках небольшого временного интервала в разных октавных, динамических и тембральных вариантах, создает особого рода мерцание, усиливающее образную сторону произведения. Таким образом, в этом произведении мы находим подтверждение тезиса о значимости колористической составляющей в произведениях Жанны Демесьё. Отметим, что эта особенность является отличительной чертой французской музыки в целом (не только органной).

Помимо рассмотрения конструктивных моментов, следует обратить внимание на содержательную сторону произведений Жанны Демесьё и их особую одухотворенность. При всей их логической выстроенности и технической сложности на первый план их семантической организации выходит смысловая 
и образная составляющая, открывающая перед нами глубокий внутренний мир автора и его совершенное мастерство.

Научная новизна. В статье были собраны биографические данные, содержащиеся в разрозненных и эпизодических англо- и франкоязычных публицистических текстах, а также проведен авторский анализ музыкального материала, позволивший выявить наиболее существенные моменты композиторского стиля замечательной французской органистки.

Выводы. За свою, к сожалению, недолгую жизнь Жанна Демесьё сумела достичь высочайшего уровня мастерства, оказать большое влияние на формирование мирового искусства и французской органной музыки, в частности. Наследуя многовековые тенденции французской органной музыки и преломляя их сквозь призму современной для нее эпохи, Жанна Демесьё синтезирует в своем творчестве отдельные традиционные для французской школы жанрово-стилевые моменты (среди которых: обращение к религиозно-программной тематике и к григорианскому хоралу, колористичность) с ярко индивидуальными чертами (гармонический язык, детальная мотивная проработка музыкальной ткани, глубокая содержательность и др.). Ее произведения по праву занимают высокое место в анналах мировой органной музыки.

\section{СПИСОК ЛИТЕРАТУРЫ}

1. Кривицкая Е.Д. История французской органной музыки : дисс. доктора искусствоведения : 18.06.2004; Моск. гос. конс. им. П.И. Чайковского. Москва, 2004. 337 с.

2. D'Arcy Trinkwon. Jeanne Demessieux: Portrait of a star. Organists' Rewiew, November, 2008.

3. Dufourcq N. La musique d'orgue franzaise de Jehan Titelouze a Jehan Alain. Paris, 1941.

4. Jeanne Demessieux. Musica et memoria. URL : http://www. musimem.com/demessieux.htm (дата обращения: 13.11.2018).

\section{REFERENCES}

1. Krivitskaya, E.D. (2004). History of French Organ Music: Doctor's thesis. Moscow [in Russian].

2. D'Arcy, Trinkwon. (2008). Jeanne Demessieux: Portrait of a star. Organists' Rewiew, November. Retrieved from https://organistsreview. com [in English].

3. Dufourcq, N. (1941). The French organ music from Jehan Titelouze to Jehan Alain. Paris [in French].

4. Jeanne Demessieux. Musica et memoria. Retrieved from http:// www.musimem.com/demessieux.htm [in French]. 